\title{
Anestésicos locais utilizados na Odontologia: uma revisão de literatura
}

\author{
Local anesthetics used in Dentistry: a literature review \\ Anestésicos locales utilizados en la Odontología: una revisión de literatura \\ Hannah Taynnan de Lima Bezerra RABÉLO ${ }^{1}$ \\ José Henrique de Araújo $\mathbf{C R U Z}^{\mathbf{1}}$ \\ Gymenna Maria Tenório GUÊNES ${ }^{2}$ \\ Abrahão Alves de OLIVEIRA FILHO² \\ Maria Angélica Satyro Gomes ALVES ${ }^{2}$
}

${ }^{I}$ Acadêmico(a), Curso de Graduação em Odontologia. Centro de Saúde e Tecnologia Rural, Universidade Federal de Campina Grande - UFCG 58708-110 Patos/PB, Brasil ${ }^{2}$ Professor(a) Doutor(a), Curso de Graduação em Odontologia. Centro de Saúde e Tecnologia Rural, Universidade Federal de Campina Grande - UFCG 58708-110 Patos/PB, Brasil

\section{Resumo}

Introdução: Os anestésicos locais são substâncias químicas capazes de bloquear de forma reversível a transmissão de impulsos nervosos no local onde forem aplicados, sendo fundamentais no âmbito da Odontologia para controle da dor. Objetivo: Realizar revisão de literatura sobre os principais anestésicos locais utilizados na Odontologia. Metodologia: O estudo trata-se de uma revisão narrativa realizada entre os meses de janeiro e março de 2018. As bases de dados para a busca da literatura foram Scielo, Pubmed, Web of Science, Bireme. As palavraschaves usadas foram "Anestésicos Locais", "Mecanismos de Ação", "Farmacologia", "Odontologia", "Relação Estrutura-atividade", "Canais de Sódio", presentes no DeCS. Discussão: A cocaína foi o primeiro composto a ser utilizado como anestésico local e foi a partir desta que os novos anestésicos foram desenvolvidos. Os anestésicos locais apresentam na sua estrutura molecular um anel aromático, uma cadeia intermediária e um grupo amina. Eles atuam sobre os neurônios e seu sítio de ação são os canais de sódio dependente de voltagem, aos quais se ligam reversivelmente, abolindo a excitabilidade neuronal. A classificação dos anestésicos locais é definida quanto à estrutura química e quanto à duração de ação, sendo os principais utilizados na Odontologia lidocaína, mepivacaína, articaína, prilocaína, cloridrato de bupivacaína. Conclusão: Conforme a literatura revisada, é necessário o conhecimento do cirurgião-dentista sobre as características farmacológicas individuais dos anestésicos locais e as sistêmicas do paciente para uma escolha correta, já que sua utilização é variável para cada usuário, e a manipulação inadequada desses fármacos pode levar a sérios riscos para a saúde do paciente.

Descritores: Odontologia; Anestésicos locais; Farmacologia; Relação Estrutura-Atividade; Canais de Sódio; Mecanismos Moleculares de Ação Farmacológica.

\section{Abstract}

Introduction: Local anesthetics are chemical substances capable of reversibly blocking the transmission of nerve impulses where it is applied and are fundamental in the field of dentistry for pain control. Objective: To review the literature on the main local anesthetics used in dentistry. Methodology: The study is a narrative review conducted between January and March 2018. The databases for literature search were Scielo, Pubmed, Web of Science, Bireme. The keywords used were "Local Anesthetics", "Mechanisms of Action", "Pharmacology", "Dentistry", "Structure-activity relation", "Sodium channels", present in DeCS. Discussion: Cocaine was the first compound to be used as a local anesthetic and it was from this that the new anesthetics were developed. Local anesthetics have in their molecular structure an aromatic ring, an intermediate chain and an amine group, they act on the neurons, their site of action are the voltage-dependent sodium channels, to which they bind reversibly, abolishing neuronal excitability. The classification of local anesthetics is defined in terms of chemical structure and duration of action, the main ones being used in dentistry lidocaine, mepivacaine, articaine, prilocaine and bupivacaine hydrochloride. Conclusion: According to the literature reviewed, it is necessary to know the dental surgeon about the individual pharmacological characteristics of the local and systemic anesthetics of the patient for a correct choice, since their use is variable for each user, and the inadequate manipulation of these drugs can serious risks to the patient's health.

Descriptors: Dentistry; Anesthetics, Local; Pharmacology; Structure-Activity Relationship; Sodium Channels; Molecular Mechanisms of Pharmacological Action.

\section{Resumen}

Introducción: Los anestésicos locales son sustancias químicas capaces de bloquear de forma reversible la transmisión de impulsos nerviosos en el lugar donde se aplica, siendo fundamentales en el ámbito de la Odontología para el control del dolor. Objetivo: Revisar la literatura sobre los principales anestésicos locales utilizados en la Odontología. Metodología: El estudio se trata de una revisión narrativa realizada entre los meses de enero y marzo de 2018. Las bases de datos para la búsqueda de la literatura fueron Scielo, Pubmed, Web of Science, Bireme. Las palabras clave usadas fueron "Anestésicos locales", "Mecanismos de Acción", "Farmacología", "Odontología", "Relación Estructura-actividad", "Canales de Sodio", presentes en el DeCS. Discusión: La cocaína fue el primer compuesto a ser utilizado como anestésico local y fue a partir de ésta que los nuevos anestésicos fueron desarrollados. Los anestésicos locales presentan en su estructura molecular un anillo aromático, una cadena intermedia y un grupo amina, que actúan sobre las neuronas, su sitio de acción son los canales de sodio dependiente de voltaje, a los que se ligan reversiblemente, aboliendo la excitabilidad neuronal. La clasificación de los anestésicos locales se define en cuanto a la estructura química y en cuanto a la duración de la acción, siendo los principales utilizados en la Odontología lidocaína, mepivacaína, articaína, prilocaína, clorhidrato de bupivacaína. Conclusión: Conforme a la literatura revisada, es necesario el conocimiento del cirujano-dentista sobre las características farmacológicas individuales de los anestésicos locales y las sistémicas del paciente para una elección correcta, ya que su utilización es variable para cada usuario, y la manipulación inadecuada de esos fármacos puede llevar a serios riesgos para la salud del paciente.

Descriptores: Odontología; Anestésicos Locales; Farmacología; Relación Estructura-Actividad; Canales de Sodio; Mecanismos Moleculares de Acción Farmacológica.

\section{INTRODUÇÃO}

A dor pode ser definida como uma experiência subjetiva, sendo uma resposta do organismo a uma experiência sensitiva e emocional desagradável de um estímulo nocivo associado a uma lesão tecidual ${ }^{1,2}$. Os fármacos modificam mecanismos periféricos ou centrais de detecção e elaboração da informação dolorosa, diminuindo a reação emocional à dor ${ }^{3}$. Os anestésicos locais (ALs), agem bloqueando reversivelmente o processo de excitação-condução em nervos periféricos, sendo de fundamental importância para Odontologia ${ }^{4,5}$.

Os anestésicos locais são substâncias químicas capazes de bloquear de forma reversível a transmissão de impulsos nervosos, inibindo a 
percepção das sensações, sobretudo dolorosas, sem ocasionar alterações no nível da consciência ${ }^{6}$. A molécula de um anestésico local (AL) apresenta em uma das extremidades um anel aromático lipofílico, uma cadeia intermediária e na outra extremidade da molécula um terminal amina ${ }^{7}$. Desta maneira, distinguem-se dois grupos diferentes de anestésicos locais, os ésteres e as amidas ${ }^{4,8}$.

Os ALs são bases fracas, pouco solúveis em água e instáveis em exposição ao ar. Estão clinicamente disponíveis sob a forma de sais, para elevar os níveis de solubilidade e estabilidade? $\mathrm{O}$ mecanismo de ação dos ALs ocorre pelas interações entre eles e a membrana do axônio, por meio do bloqueio de canais iônicos na membrana neuronal, impedindo a neurotransmissão ${ }^{10}$. A forma ionizada do AL se liga aos canais de sódio ( $\mathrm{Na}+)$, inativandoos e impedindo a propagação da despolarização celular $^{11,12}$.

As propriedades ideais de um AL são: baixa toxicidade, não irritar os tecidos, não lesionar as estruturas nervosas, ser eficaz, possuir o menor tempo de latência, a duração deve ser longa, embora não excessivamente longa ${ }^{4,13}$. Dentre os ALs, os utilizados com maior frequência no âmbito odontológico podem ser citados lidocaína, mepivacaína, articaína, prilocaína e bupivacaína ${ }^{14}$. Os anestésicos são de grande valor para Odontologia, haja vista que a dor está fortemente vinculada ao tratamento odontológico e estando esta associada ao medo ${ }^{15}$.

Desse modo, este estudo tem por objetivo realizar uma revisão de literatura sobre os principais anestésicos locais utilizados na Odontologia.

\section{MATERIAL E MÉTODO}

Trata-se de estudo de revisão de literatura narrativa realizada entre os meses de janeiro e março de 2018. Foram utilizadas como base de dados Scielo - http://www.scielo.org/php/index.php; Pubmed https://www.ncbi.nlm.nih.gov/pubmed/; Web of Science - https://webofknowledge.com/; Bireme http://bvsalud.org/. Foram selecionadas 46 literaturas. Como descritores foram utilizados "Anestésicos Locais", "Farmacologia", "Odontologia", "Relação Estrutura-atividade", "Canais de Sódio" e "Mecanismos de Ação Farmacológica", presentes no DeCS.

\section{RESULTADOS E DISCUSSÃO}

\section{- Descoberta dos anestésicos locais}

Das folhas de arbustos da família Erithroxylonacea foi descoberto o primeiro composto a ser utilizado como AL, a cocaína. Os nativos dos Andes faziam uso dessa planta devido à redução da fome e aumento da resistência física que obtinham ao mascarem suas folhas. Quando levadas à Europa por exploradores europeus, constatou-se a propriedade de promover insensibilidade ${ }^{16}$.
Em 1855, Gaedicke isolou um alcaloide das folhas da Erythroxylon coca, a eritroxilina, a partir da qual, Albert Niemann em 1860, obteve cristais puros com sabor amargo, aos quais deu o nome de cocaína. Estudos conduzidos pelos farmacologistas Schroff e Von Anrep, entre 1862 e 1880, mostraram que a cocaína, ao ser administrada por via oral ou aplicada localmente, causava midríase, vasoconstrição de artérias periféricas e entorpecimento da língua, levando Von Anrep a crer numa provável importância clínica. Em 1884, Karl Köller introduziu a cocaína na prática clínica como um anestésico de uso tópico em cirurgias oftalmológicas 17,18,19,20 $^{\text {. }}$

A cocaína apresentava um alto grau de efeitos tóxicos como dependência física e psíquica, e iniciou-se a pesquisa para a descoberta de substituintes sintéticos da mesma. Em 1905, Ein Horn realizou a síntese da procaína, a qual se tornou o protótipo para os anestésicos locais por aproximadamente meio século. Até que em 1943, Löfgren sintetizou a lidocaína, originando, assim, a era dos ALs do tipo amida, relativamente isentos de reações alérgicas e que são mais utilizados atualmente ${ }^{16,19}$.

\section{- Estrutura química dos anestésicos locais}

A estrutura molecular de um AL define seus efeitos clínicos. Reconhecem-se, na fórmula geral destes, três partes fundamentais: radical aromático, cadeia intermediária e grupo amina.

$\mathrm{O}$ radical aromático se caracteriza por um grupamento lipofílico, responsável por sua penetração no nervo. Entre os exemplos de radicais aromáticos podemos citar o ácido benzoico (cocaína, benzocaína), o ácido para-aminobenzóico (procaína) e a xilidina (lidocaína, bupivacaína). A xilidina praticamente não provoca reações alérgicas, já o ácido para-aminobenzóico pode levar a tais reações ${ }^{4,8,21,22}$.

Esqueleto da molécula do anestésico, a cadeia intermediária fornece a separação espacial necessária entre as extremidades lipofílica e hidrofílica. Variações da cadeira intermediária influenciam no metabolismo, toxicidade e alergenicidade dos ALs. Conforme a natureza química formam-se dois grupos diferentes de ALs, os ésteres e as amidas. Ésteres apresentam ligação éster unindo os grupamentos lipofílico e hidrofílico, sendo biotransformados rapidamente pela colinesterase plasmática. Amidas apresentam ligação amida unindo os dois grupamentos e são biotransformadas pelos microssomos hepáticos ${ }^{4,8,21,22}$.

Por fim o grupamento amina, enquanto grupamento hidrofílico, é a porção ionizável da molécula que sob influência do $\mathrm{pH}$ do meio determina a velocidade de ação do $\mathrm{AL}^{4,8,21,22}$.

A capacidade de penetração de um AL no tecido nervoso varia conforme sua lipossolubilidade. Quanto mais lipofílico se apresentar, maior será a sua 
capacidade de penetração, potencializando sua ação e duração $^{23}$. O grau de lipossolubilidade também determina a dificuldade de excreção do AL pelos rins, de forma que os mais lipossolúveis são mais difíceis e gerarem toxicidade ${ }^{22}$.

As diferentes proporções de componentes hidrofílicos e lipofílicos dos diversos ALs modificam as suas características e/ou propriedades alterando: potência intrínseca, início de ação, duração do efeito anestésico, metabolismo da droga e toxicidade.

A potência intrínseca do anestésico corresponde à concentração mínima de um agente $\mathrm{AL}$ que reduz o potencial nervoso à metade de sua amplitude em 5 minutos. É uma medida de ação farmacológica do agente ${ }^{15,23,24}$. A velocidade com a qual o agente atravessa o tecido, a proximidade do sítio de injeção do nervo a ser anestesiado e o diâmetro das fibras nervosas determinam o início de ação do AL. Fibras mais finas são anestesiadas mais rapidamente se comparadas com fibras mais espessas, provavelmente devido à maior proximidade dos nódulos de Ranvier entre $\mathrm{si}^{15,23,24}$. O tempo de duração anestésica é dependente do fluxo de difusão de um gradiente de concentração para longe de seu sítio de ação, representado pelos canais iônicos presentes na membrana da célula nervosa ${ }^{15,23,24}$. Altos níveis de AL podem afetar órgãos e tecidos que contêm lipídios . A atividade terapêutica, e também a tóxica dos ALs, é atribuída ao bloqueio dos canais de $\mathrm{Na}^{+}$quando o fármaco exerce a sua função sobre a membrana da célula. À medida que as concentrações de AL aumentam, as vias inibidoras e excitatórias do cérebro vão sendo suprimidas, e a toxicidade cardiovascular (arritmias e depressão miocárdica) fica evidente após os níveis plasmáticos já terem comprometido o sistema nervoso central ${ }^{15,23,24}$.

O metabolismo sistêmico e local dos ALs difere nos grupos amida e éster: do grupo amida são biotransformados no fígado e subsequentemente conjugados com ácido glicurônico, sendo excretados na urina. Os ALs do grupo éster são biotransformados pela colinesterase plasmática e são amplamente distribuídos no corpo ${ }^{15,23,24}$.

\section{- Relação estrutura-atividade}

Entende-se por relação estrutura-atividade o estudo dos efeitos obtidos a partir de variações na estrutura química de determinado fármaco, bem como os principais fatores que influenciam a sua interação com o local alvo ${ }^{8}$. Todos os anestésicos locais são bases fracas, pouco solúveis em água e instáveis na exposição ao ar. Os seus valores de $\mathrm{pKa}$ ( $\mathrm{pH}$ no qual estes apresentam as mesmas concentrações da base e do seu ácido conjugado) variam de 7,5 a 10,0. O fato dos ALs apresentarem um pKa elevado, faz com que eles se liguem a ácidos para formar sais, apresentando maior solubilidade em água e se tornando comparativamente mais estáveis. Por isso, as preparações farmacêuticas (sais de hidrocloreto) são levemente ácidas, com $\mathrm{pH}$ variando de 4,5 a 6,0 nos tubetes odontológicos ${ }^{4,9}$. No organismo, os ALs, ocorrem como base sem carga ou como cátion. As proporções relativas dessas duas formas são determinadas pelo $\mathrm{pKa}$ e pelo $\mathrm{pH}$ dos líquidos corporais, de acordo com a equação de Henderson-Hasselbach ${ }^{9}$ (Figura 1).

$$
\log \frac{\text { forma catiónica }}{\text { forma sem carga }}=p K a-p H
$$

Figura 1: Equação de Henderson-Hasselbach ${ }^{9}$

$\mathrm{O}$ pKa dos ALs determina a quantidade de droga existente na forma ionizada em um determinado $\mathrm{pH}$. Como o pKa da maioria dos ALs se situa entre os 8,0 e 9,0, os compostos estarão maioritariamente na forma catiônica, esta constitui a forma mais ativa no local receptor porque não pode sair facilmente pelos canais fechados. No entanto, a fração sem carga em $\mathrm{pH}$ fisiológico alcança seu sítio efetor com mais rapidez, sendo assim importante para a rápida penetração através das membranas biológicas $^{25,26}$.

O meio extracelular apresenta uma constante variação do $\mathrm{pH}$, diferente do meio intracelular. Assim, a função dos ALs é alterada pelas oscilações no $\mathrm{pH}$ extracelular'. Em um local ácido irá haver uma ação reduzida do anestésico. Por isso administrar soluções anestésicas nas áreas com inflamação ou infectadas é arriscado, pois um tecido sadio apresenta um $\mathrm{pH}$ de 7,4, enquanto que o $\mathrm{pH}$ de uma área inflamada é entre 5,0 e $6,0^{4,26}$. As alterações no anel aromático do grupo amino pode modificar a hidrofobicidade, afetando a capacidade com que o $\mathrm{AL}$ atravessa as membranas das células nervosas ${ }^{6}$. Um anestésico local eficaz deve distribuir-se na membrana e dissociar-se dela ${ }^{27}$.

Os ALs pouco hidrofóbicos são incapazes de atravessar eficientemente a membrana. Na Figura 2, o AL neutro não pode penetrar na membrana celular (1) uma vez que o AL é muito estável na solução extracelular e necessita de uma energia de ativação elevada para que possa ocorrer a penetração ${ }^{9}$. Os ALs moderadamente hidrofóbicos são mais eficazes comparados aos pouco hidrofóbicos. Na figura 3, o AL neutro sofre adsorção do lado extracelular da membrana (1), em (2) observa-se a difusão do AL através da membrana para o lado citoplasmático, seguidamente, em (3), ocorre difusão no lado intracelular e o AL liga-se a seu local de ligação no canal de $\mathrm{Na}^{+}$regulado por voltagem, finalmente, em (4), o AL passa de forma neutra a protonada através de ligação e liberação de prótons ${ }^{6}$.

Observa-se na Figura 4 que os ALs muito hidrofóbicos são retidos na dupla camada lipídica. Em (1) o AL neutro sofre adsorção do lado extracelular da membrana, onde fica estabilizado que não consegue dissociar da membrana nem a atravessar como se vê em (2), com isso, o fármaco 
não consegue exercer sua função anestésica ${ }^{9,28}$.

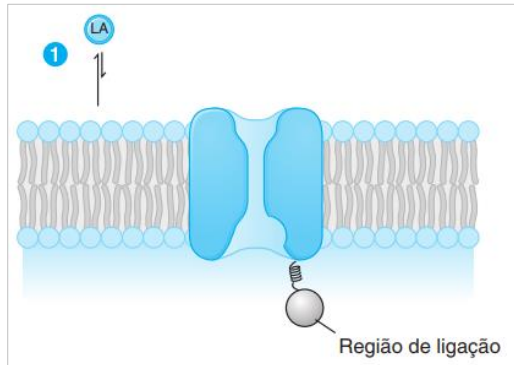

Figura 2: Representação esquemática de um AL pouco hidrofóbico (Adaptado de Golan et al. ${ }^{28}$ ).

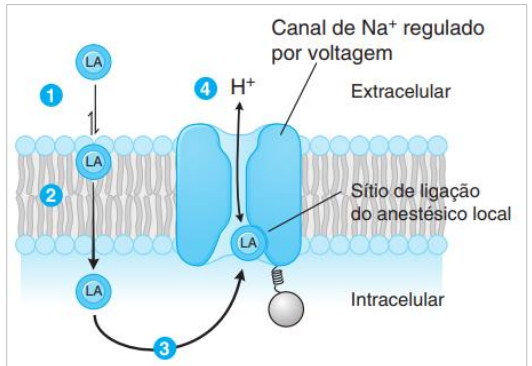

Figura 3: Representação esquemática de um AL moderadamente hidrofóbico (Adaptado de Golan et al. ${ }^{28}$ ).

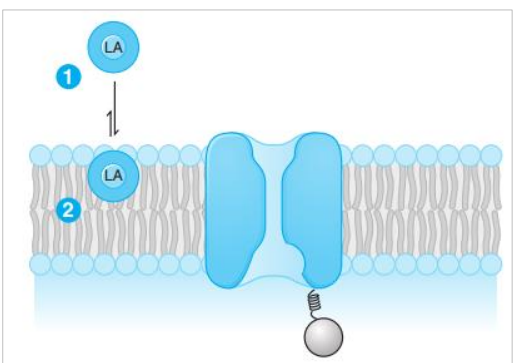

Figura 4: Representação esquemática de um $\mathrm{AL}$ extremamente hidrofóbico (Adaptado de Golan et al..$^{28}$ ).

Os ALs neutros atravessam as membranas mais facilmente comparado às formas com cargas positivas. Porém, as formas com cargas positivas se ligam com maior afinidade ao local alvo de ligação, conferindo maior duração anestésica. A benzocaína, não-ionizável, é permanentemente neutra, mas tem a capacidade de bloquear os canais de $\mathrm{Na}^{+}$e os potenciais de ação, porém o bloqueio é fraco e não depende do $\mathrm{pH}$ extracelular ${ }^{22}$. Quanto mais hidrofóbico o fármaco maior será a potência e a duração de ação. Esta também depende da ligação às proteínas; vasoconstritores, como a adrenalina; e da resistência à hidrólise; as ligações éster são mais facilmente hidrolisadas que as ligações amida ${ }^{8}$.

\section{- Mecanismo de ação}

\section{- Considerações anatômicas}

Os neurônios, em sua grande maioria, são compostos de dendritos, de um corpo celular e um axônio. Os dendritos transmitem a informação ao longo do neurônio e do seu corpo celular para os axônios, os quais fazem sinapse com outros neurônios. Alguns axônios neuronais possuem mielina, membranas de células de suporte, formam uma bainha de isolamento elétrico, que aumenta a velocidade de transmissão dos impulsos ${ }^{13,29}$. As fibras nervosas podem ser classificadas em fibras A, fibras B e fibras C. As fibras do grupo A possuem os maiores diâmetros e bainha de mielina espessa, conduzindo impulsos em velocidade de até 150 metros por segundo $(\mathrm{m} / \mathrm{s})$. Fibras do grupo B são levemente mielinizadas e de diâmetro intermediário, transmitem impulsos em uma frequência média de $15 \mathrm{~m} / \mathrm{s}$. Fibras do grupo $\mathrm{C}$ possuem os menores diâmetros, são amielínicas e conduzem impulsos a $1 \mathrm{~m} / \mathrm{s}$ ou menos ${ }^{29}$.

As fibras nervosas são circundadas por três membranas protetoras ou bainhas: o epineuro, o perineuro e o endoneuro. Os ALs são injetados fora da bainha mais externa, o epineuro, para evitar a lesão mecânica do nervo causada pela agulha. O fármaco atravessa as bainhas, sendo o perineuro a camada mais difícil para penetração dos ALs, devido à presença de junções firmes as suas células ${ }^{27}$. Na Figura 5, pode-se observar em (1) que o AL é injetado fora do epineuro. Em (2), as moléculas de $\mathrm{AL}$ devem atravessar o epineuro para alcançar o perineuro. A seguir, em (3) o AL penetra no endoneuro, que envolve as fibras mielinizadas e amielínicas, as células de Schwann e os capilares. Apenas os ALs que atravessam essas três bainhas poderão atingir os canais de $\mathrm{Na}^{+}$regulados por voltagem $^{27}$.

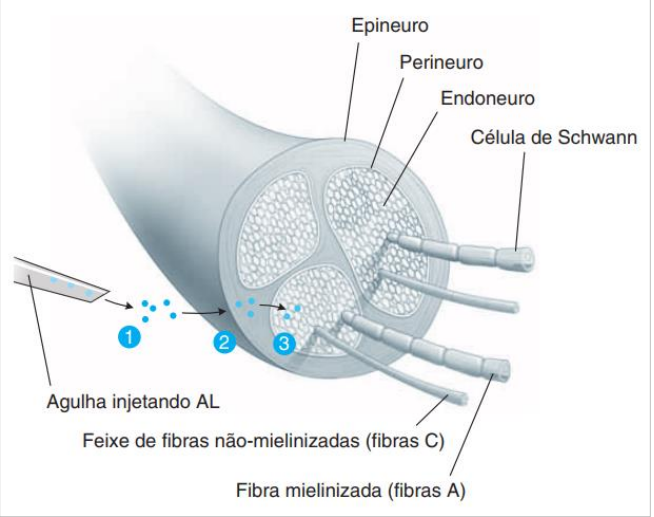

Figura 5: Anatomia de um nervo periférico (Golan et al. $\left.{ }^{28}\right)$.

\section{- Canal de sódio dependente de voltagem}

$\mathrm{O}$ canal de $\mathrm{Na}^{+}$é uma glicoproteína de membrana que se encontra em axônios e músculos e ativada pela despolarização. $\mathrm{O}$ potencial elétrico determina a probabilidade de abertura desses canais, que permitem fluxo eletrodifusional apenas de $\mathrm{Na}^{+19,30}$. Os canais de $\mathrm{Na}^{+}$dependente de voltagem são os mais estudados. São responsáveis pela permeabilidade de $\mathrm{Na}^{+}$em resposta à alteração de voltagem, iniciando os potenciais de ação nas células. São compostos por uma subunidade $\alpha$ podendo estar associada a quatro tipos de subunidades $\beta$. Estes canais determinam a especialização funcional de neurônios sensoriais e células cardíacas, principalmente em processos fisiológicos, como dor, inflamação e contratilidade ${ }^{13,19}$.

Admite-se que o canal de $\mathrm{Na}^{+}$exista em três 
estados de conformação: aberto, inativo e em repouso. Bem como várias conformações "fechadas" "transitórias" 21,27 . Em repouso, o potencial é de -60 a -70 milivolts $(\mathrm{mV})$. Durante um potencial de ação, os canais em repouso passam para conformações fechadas e, por fim, abrem-se por um breve período para permitir a entrada de íons $\mathrm{Na}^{+}$. Esse influxo de $\mathrm{Na}^{+}$resulta em despolarização da membrana. O canal aberto sofre uma mudança de sua conformação, assumindo o estado inativo. Isso interrompe o influxo de $\mathrm{Na}^{+}$, contribuindo para a repolarização ${ }^{27}$.

O canal inativado retorna lentamente ao repouso na membrana repolarizada. Durante o período refratário, existe um número pequeno de canais de $\mathrm{Na}^{+}$no estado de repouso que mesmo se todos fossem abertos o limiar não seria alcançado. Dessa forma, nenhum potencial de ação novo pode ser gerado durante esse período ${ }^{27}$. Substâncias com efeitos sobre canais de $\mathrm{Na}^{+}$fazem-no por se ligarem à subunidade $\alpha$. Algumas se ligam a sítios extracelulares, próximos ao poro e o obstruem, bloqueando o fluxo de íons pelo canal. Outras ligamse a sítios específicos e modificam o processo de "gating" do canal, de ativação ou de inativação ${ }^{30}$. O AL age pelo lado intracelular e tem que penetrar na célula para ter efeito. A penetração se dá por difusão simples ${ }^{20}$. O bloqueio dos canais de $\mathrm{Na}^{+}$dependente de voltagem pelos ALs impedem a geração de potenciais de ação. Sem potenciais de ação, um neurônio não transmite informações, como dor, da periferia para o sistema nervoso central, onde é gerada a sensaçãa ${ }^{30}$.

\section{- Hipótese do Receptor Modulado}

Quando aplicados em terminações nervosas ou em troncos nervosos condutores de sensibilidade, os ALs bloqueiam transitoriamente a transmissão do potencial de ação ${ }^{11,12}$. Basicamente, os estes fármacos previnem tanto a condução quanto a geração de impulsos nervosos, à semelhança de um isolante ${ }^{22}$. Os ALs interagem com os estados funcionais do canal de $\mathrm{Na}^{+}$(repouso, vários fechados, aberto, inativado). Assim, o AL se liga preferencialmente à forma inativada do canal, não condutora, mantendose nesta forma e estabilizando a membrana (Figura 6) ${ }^{21,30}$.

Embora o AL se ligue a um sítio no poro do canal de $\mathrm{Na}^{+}$, o mecanismo molecular de inibição do canal envolve tanto a oclusão física do poro, como também a restrição da ativação do canal ${ }^{27}$. Para que ocorra reabertura de um canal, o AL precisa dissociar-se do canal e permitir que o canal retorne a seu estado de repouso. Essa dissociação do fármaco é mais lenta do que a recuperação normal da conformação inativada do canal para a de repouso na ausência de um AL. Os ALs estendem o período refratário do neurônio ao retardar o retorno do canal inativado ao estado de repouso em cerca de 50 a 100 vezes. Em altas concentrações, os ALs se ligam a um número suficiente de canais de repouso de baixa afinidade para impedir a condução do impulso ${ }^{27}$. Quanto maior o número de canais inativados houver, maior será a facilidade do bloqueio. Quanto maior a frequência de estímulos de uma fibra, mais canais se abrem, se fecham e se inativam. O bloqueio do canal de $\mathrm{Na}^{+}$é proporcional à frequência dos impulsos despolarizantes, que fazem com que mais canais inativados apareçam ${ }^{21}$.

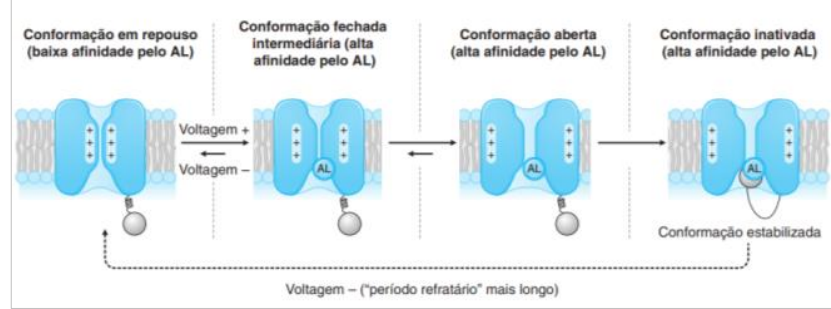

Figura 6: Ligação de um AL a diferentes conformações (estados) do canal de $\mathrm{Na}^{+}$

\section{- Classificação dos anestésicos locais}

Atualmente os ALs podem ser classificados de duas maneiras: Quanto à estrutura química, éster ou amida, e quanto à duração de ação como de curta, intermediária ou longa duração de ação ${ }^{23}$. Além da cocaína, fazem parte do grupo éster a procaína, cloroprocaína, tetracaína e benzocaína. Destes, a benzocaína é o único atualmente empregado em Odontologia. O poder de sensibilização alérgica do grupo dos ésteres é devido a um dos seus produtos metabólicos, o ácido para-aminobenzóico ${ }^{31}$. As amidas surgiram a partir de 1948 com a síntese da lidocaína. Este grupo apresenta menor capacidade em produzir reações alérgicas. Além da lidocaína: mepivacaína, prilocaína, articaína, bupivacaína, ropivacaína e etidocaína compõem o grupo ${ }^{9,31}$. As drogas de curta duração são aquelas que produzem cerca de 30 minutos de anestesia pulpar. As de média duração produzem cerca de 60 minutos de anestesia pulpar e as de longa duração produzem mais de 90 minutos de anestesia pulpar'.

\section{- Soluções anestésicas}

Os ALs permitem um melhor e adequado controle da dor em pacientes que se submetem a tratamentos dentários ${ }^{32}$. Devem ser considerados alguns fatores para a seleção e o emprego dos ALs, como o tempo de duração e necessidade de hemostasia durante o procedimento, o desconforto ou automutilação após a intervenção, a quantidade máxima recomendada, os efeitos adversos e contraindicações dos sais anestésicos e seus vasoconstritores ${ }^{12,15}$.

\section{- Lidocaína}

A lidocaína é o AL é considerado o anestésico padrão em Odontologia. Foi o primeiro agente anestésico do grupo amida a ser sintetizado. Este anestésico apresenta maior hidrofobicidade, o que reduz a sua velocidade de hidrólise, além de apresentar um valor baixo de $\mathrm{pKa}$, resultando num 
rápido bloqueio ${ }^{4,33}$. A duração de ação deste fármaco baseia-se em dois fatores: hidrofobicidade moderada e ligação amida. Esta impede a degradação do fármaco pelas esterases e a sua hidrofobicidade permite permanecer no local onde é administrado. Além disso, tem baixo poder alergênico ${ }^{13}$.

Encontra-se lidocaína com ou sem adrenalina ou outros vasoconstritores. A adrenalina é o vasoconstritor mais utilizado e se apresenta em concentrações de 1:50.000, 1:100.000 e 1:200.0009 . As propriedades vasodilatadoras da lidocaína reduzem o seu tempo de ação quando utilizada sem vasoconstritor (5 a 10 minutos), no entanto, quando associada a um vasoconstritor a duração de anestesia aumenta (1 a 2 horas) ${ }^{34}$. Na Odontologia, apresentase na forma de lidocaína $2 \%$. Sua dose máxima recomendada é de 7,0 miligramas por quilograma $(\mathrm{mg} / \mathrm{kg})$ em adultos, não excedendo 500 miligramas (mg) ou 13 tubetes anestésicos ${ }^{9,35}$. A lidocaína é rapidamente metabolizada pela oxidação microssomal no fígado. Sua eliminação é renal, e $10 \%$ são excretados inalterados. As reações alérgicas a esse fármaco são extremamente raras ${ }^{36}$.

Em idosos recomenda-se a utilização de lidocaína $2 \%$ com adrenalina na diluição de 1:200.000 ou 1:100.000, não ultrapassando a dose de $0,04 \mathrm{mg}$ de adrenalina por consulta, pois idosos são mais sensíveis aos vasoconstritores ${ }^{37}$. A lidocaína é o anestésico mais seguro para gestantes, pois é associada a adrenalina 1:100.000, com utilização de no máximo 2 tubetes por atendimento. Também é segura para utilização em crianças, com adrenalina 1:200.000, sendo a dose máxima com ou sem vasoconstritor um tubete de anestésico para cada 9,09 quilograma $(\mathrm{kg})^{9}$.

Algumas manifestações cardíacas podem ocorrer quando a lidocaína for utilizada combinada com outro agente antiarrítmico, como a bradicardia, hipotensão e colapso cardiovascular, podendo produzir distúrbios profundos na automaticidade e condução cardíacas ${ }^{14}$. A lidocaína demonstra ainda propriedades anticonvulsivantes ${ }^{38}$. Os sinais e sintomas de toxicidade da lidocaína podem ser de estimulação seguida de depressão do sistema nervoso central. Os primeiros sinais e sintomas de uma superdosagem de lidocaína podem ser sonolência, levando à perda de consciência e parada respiratória ${ }^{39}$.

\section{Mepivacaína}

A mepivacaína pertence ao grupo das amidas, é amplamente utilizada na Odontologia, tendo duração intermediária. É metabolizada no fígado e seus produtos finais excretados pelos rins, onde $1 \%$ a $16 \%$ da dose aplicada são excretadas inalteradas ${ }^{8,15}$. Possui ação vasodilatadora menor que a lidocaína, porém, a mepivacaína sem vasoconstritor apresenta uma duração de efeito anestésico de 20 a 40 minutos. Todavia, com vasoconstritores, atinge períodos de 3 a
5 horas de anestesia local ${ }^{8,40}$. Apresenta potência e toxicidade duas vezes maior que a lidocaína, tendo o seu início de ação 1,5 a 2 minutos. A dose máxima é de $6,6 \mathrm{mg} / \mathrm{kg}$, não devendo ultrapassar $400 \mathrm{mg}$ ou 11 tubetes anestésicos. A concentração odontológica eficaz é de $2 \%$ (com vasoconstritor) e de $3 \%$ (sem vasoconstritor $)^{9,35}$.

Existem três vasoconstritores que podem ser associados à mepivacaína: levonordefrina (1:20.000), noradrenalina $(1: 100.000)$ e adrenalina $(1: 100.000)$. A mepivacaína se distingue da lidocaína por produzir apenas vasodilatação. Recomenda-se utilizar um AL sem vasoconstritor, como a mepivacaína 3\%, nos tratamentos de urgência em pacientes com pressão arterial descompensada 9 . A mepivacaína apresenta uma duração mais curta tornando-se útil em odontopediatria, que apresenta frequentes lesões de mordedura. A duração de permanência em meios pulpares com mepivacaína é mais curta ${ }^{4}$ A incidência de alergia é praticamente inexistente e os sinais e sintomas de superdosagem de mepicavaína geralmente seguem a estimulação do SNC seguida de depressão ${ }^{39}$.

\section{- Articaína}

A articaína é o único anestésico contendo anel tiofeno substituindo o clássico anel bezênico, aumentando a sua solubilidade em lipídios. Ao contrário de outros ALs, a articaína contém um grupo éster adicional e a sua meia-vida é de aproximadamente 20 minutos, sendo esta considerada curta. Assim, é rapidamente eliminada da circulação através dos rins, diminuindo a toxicidade associada à redução lenta da droga no local da injeção ${ }^{8,41}$. No Brasil a articaína possui duas formulações: $4 \%$ com adrenalina a 1:100.000 ou 1:200.000. Sua dose máxima recomendada é de $6,6 \mathrm{mg} / \mathrm{kg}$, não ultrapassando $500 \mathrm{mg}$ ou 6 tubetes $^{36,39,40}$. Qualquer das formulações não prejudica a sua eficácia clínica: latência, analgesia pós-operatória e qualidade da anestesia. A concentração de 1:100.000, possibilita melhor a visualização e controle do sangramento ${ }^{42-44}$.

O efeito colateral da articaína é a metahemoglobinemia, reação percebida após administração acidental intravenosa, mas nenhum caso foi reportado quando da administração da maneira e volume usuais, logo, a articaína é contraindicada em pacientes com metahemoglobinemia idiopática ou congênita, anemia ou falha cardíaca ou respiratória evidenciada por hipóxia ${ }^{38}$. Sua biotransformação por colinesterases plasmáticas e teciduais gera um metabólito inativo, com toxicidade cardíaca e neurológica irrelevante. Devido a isso, é apropriado para ser empregado em pacientes com disfunção hepática e renal ${ }^{34}$.

\section{Prilocaína}

É um derivado amino-secundário da toluidina, de ação média e duração de ação 
intermediária, além de apresentar ação vasoconstritora intrínseca. É menos tóxica, também menos potente que a lidocaína, sendo utilizada em concentrações de $4 \%$, em lugar dos $2 \%$ da lidocaína, e possui início de ação por volta de 2 a 4 minutos $^{38}$.

A dose máxima recomendada é de $6,0 \mathrm{mg} / \mathrm{kg}$, não excedendo $400 \mathrm{mg}$ ou 7 tubetes na concentração de $4 \%$, no paciente adulto. A prilocaína quando para paciente idoso, não deve ultrapassar dois tubetes anestésicos. É o único anestésico metabolizado nos pulmões, além de no fígado, e excretado principalmente pelos rins ${ }^{9,35,39}$. O bloqueio regional do nervo fornece uma anestesia pulpar de até 60 minutos. Encontrada na concentração $3 \%$ e tendo a felipressina como vasoconstritor em concentrações de $0,03$ Unidades Internacionais por mililitro (UI/ml $)^{9,35}$.

A felipressina, hormônio sintético similar à vasopressina e constituinte de soluções anestésicas cujo sal é a prilocaína, não produz alterações significativas na frequência cardíaca. A isquemia produzida por ela não é seguida de hipóxia tecidual ${ }^{9}$.

A felipressina não deve ser usada em gestantes, por estar quimicamente relacionada com a ocitocina, que possui potencial para causar contrações uterinas ${ }^{22}$. A felipressina é relativamente contraindicada em paciente com metahemoglobinemia idiopática ou congênita, hemoglobinopatias, anemia ou insuficiência cardíaca ou respiratória evidenciada por hipóxia, reduzindo a capacidade de transporte de oxigênio ${ }^{39}$. A metahemoglobinemia é induzida por um excesso de metabólitos deste e se manifesta como cianose e leva a hipóxia tecidual ${ }^{5}$.

\section{- Cloridrato de Bupivacaína}

A bupivacaína é um AL do tipo amina com amplo tempo de ação. O único de longa duração disponível no Brasil. Sua potência é quatro vezes maior que a lidocaína devido a sua solubilidade, e apresenta uma toxicidade quatro vezes menor que a lidocaína. É metabolizada pelas amidases do fígado, sendo sua eliminação renal. Possui início de ação lento (6 a 10 minutos) e duração prolongada, pois é altamente hidrofóbica ${ }^{45}$. Apresenta uma dose máxima de $1,3 \mathrm{mg} / \mathrm{kg}$, não devendo ultrapassar $90 \mathrm{mg}$ ou 10 tubetes. A anestesia mandibular pode persistir de 5 a 9 horas 9 .

A bupivacaína é o único sal anestésico, com duração de 2 a 5 horas e até 12 horas em bloqueios nervosos periféricos ${ }^{5}$. É importante na prevenção da dor pós-operatória e quando administrada em conjunto com anti-inflamatórios não-esteroidais o período pós-operatório se torna mais confortável ${ }^{46}$. São referidas arritmias cardíacas por seu uso, e a necessidade de analgésicos opióides pós-operatórios diminui consideravelmente isso ${ }^{39}$.

A bupivacaína não é recomendada para pacientes jovens ou para aqueles que apresentam grande risco de lesão pós-operatória por automutilação, como os pacientes com deficiência física e mental. É Contraindicada para procedimentos odontopediátricos $^{39}$. Em pacientes idosos, a bupivacaína é a última opção a ser considerada, devido à sua longa duração, e quando esta for usada, deve ser utilizada com um vasoconstritor em baixa concentração (adrenalina 1:200.000) e não deve ultrapassar o equivalente ao contido em 2 tubetes anestésicos, sendo que normalmente 1 tubete é o suficiente $^{32}$.

\section{CONCLUSÃO}

Cada anestésico local possui mecanismo molecular específico de ação farmacológica, indicações e contraindicações. Conhecê-los é dever de todo cirurgião-dentista para uma prática clínica eficaz e com menor probabilidade de colocar o paciente em risco.

\section{REFERÊNCIAS}

1. Almeida FM. Controle medicamentoso da dor. In: Estrela C. Dor odontogênica. São Paulo: Artes Médicas; 2001. p.243-61.

2. Silva AP, Diniz AS, Araújo FA, Souza CC. Presença da queixa de dor em pacientes classificados segundo o protocolo de Manchester. Rev Enferm Centro Oeste Mineiro. 2013; 3(1):507-17.

3. Rang HP, Dale MM, Ritter JM, Flower RJ, Henderson G. Farmacologia. 8. ed. Rio de Janeiro: Elsevier; 2016.

4. Paiva LCA, Cavalcanti AL. Anestésicos locais em Odontologia: Uma revisão de literatura. UEPG Ci Biol Saúde. 2005; 11(2):35-42.

5. Soares RG, Salles AA, Irala LED, Limongi O. Como escolher um adequado anestésico local para as diferentes situações na clínica odontológica diária? RSBO. 2006;3(1):35-40.

6. Miller RD, Hondeghem LM. Anestésicos Locais. In: Katzung BG. Farmacologia básica e clínica. 10. ed. Rio de Janeiro: AMGH Editora; 2010. p.301-7.

7. Becker D, Reeed K. Essentials of local anesthetic pharmacology. Anesth Prog. 2006;53(3):98-108.

8. Alves RIL. Anestésicos locais [dissertação]. Porto, Portugal: Universidade Fernando Pessoa; 2013.

9. Malamed SF. Manual de anestesia local. 6. ed. Rio de Janeiro: Elsevier; 2013.

10.Ferreira AAA, Silva ID, Diniz RS, Guerra GCB. Anestésicos locais: revisando o mecanismo de ação molecular. Infarma. 2006;18(5/6):15-18.

11.Anjos ED, Carvalho RWF. Complicações sistêmicas em anestesia local. In: Lubiana NB. Pro-Odonto Cirurgia. 2. ed. Porto Alegre: Artmed; 2007. p.143-78.

12. Carvalho RWF, Pereira CU, Anjos ED, Laureano Filho JR, Vasconcelos BCE. Anestésicos locais: como escolher e prevenir complicações 
sistêmicas. Rev Port Estomatol Med Dent Cir Maxilofac. 2010;51(2):113-20.

13. Teixeira RN. Anestesia local sem vasoconstritor versus com vasoconstritor [dissertação] Porto, Portugal: Faculdade de Ciências da Saúde, Universidade Fernando Pessoa; 2014.

14. Carvalho B, Fritzen EL, Parodes AG, Santos RB, Gedoz L. O emprego dos anestésicos locais em Odontologia: revisão de literatura. Rev bras odontol. 2013;70(2):178-81.

15. Santaella GM. Soluções anestésicas locais: uma revisão de literatura [monografia]: Florianópolis: Universidade Federal de Santa Catarina; 2011.

16.Reis Jr A. Sigmund Freud (1856-1939) e Karl Köller (1857-1944) e a descoberta da anestesia local. Rev Bras Anestesiol. 2009;59(2):244-57.

17. Bobbio A. História Sinótica da Anestesia. São Paulo: Novel; 1969.

18. Byck R. Freud e a Cocaína. Rio de Janeiro: Espaço e Tempo; 1989.

19. Araújo DR, Paula E, Fraceto LF. Anestésicos locais: interação com membranas biológicas e com o canal de sódio voltagem-dependente. Quim Nova. 2008;31(7):1775-83.

20.Catterall WA, Mackie K. Local anesthetics. In: Brunton LL, Lazo JS, Parker KL. Goodman and Gillman's the pharmacologic basis of therapeutics. 11. ed. New York: McGraw Hill; 2006. p. 369-85.

21.Carvalho JCA. Farmacologia dos anestésicos locais. Rev Bras Anestesiol. 1994;44(1):75-82.

22. Faria FAC, Marzola C. Farmacologia dos anestésicos locais - considerações gerias. BCI. 2001;8(29):19-30.

23. Bahl R. Local anestesia in dentistry. Anesth Prog. 2004;51(4):138-42.

24.Udelsmann A, Dreyer E, Melo MS, Bonfim MR, Borsoi LFA, Oliveira TG. Lipídeos nas intoxicações por anestésicos locais. ABCD arq bras cir dig. 2012;25(3):169-72.

25.Fozzard HA, Lee PJ, Lipkind JM. Mechanism of local anesthetic drug action on voltage-gated sodium channels. Curr Pharm Des. 2005;11(21):2671-86.

26.Jackson T, Mclure HA. Pharmacology of local anesthetics. Ophthalmol Clin North Am. 2006;19(2):155-61.

27. Schulman JM, Strichartz GR. Farmacologia dos Anestésicos Locais. In: Golan DE, Tashjian Jr AH, Armstrong EJ, Armstrong AW. Princípios de Farmacologia: a base fisiopatológica da farmacoterapia. 2. ed. Rio de Janeiro: Guanabara Koogan; 2009. p.131-145.

28.Golan DE, Tashjian Jr AH, Armstrong EJ, Armstrong AW. Princípios de Farmacologia: a base fisiopatológica da farmacoterapia. 3. ed. Rio de Janeiro: Guanabara Koogan; 2014.

29. Marieb EM, Hoehn K. Anatomia e Fisiologia. 3. ed. Porto Alegre: Artmed; 2009.

30.Carvalho-De-Souza JL. Análise do efeito inibitório do eugenol sobre canais para $\mathrm{Na}+$ ativados por voltagem em neurônios sensitivos [tese]. São Paulo: Instituto de Ciências Biomédicas - USP; 2009.

31.Andrade ED. Terapêutica medicamentosa em Odontologia. 3. ed. Rio de Janeiro: Artes Médicas; 2014.

32.Parise GK, Ferranti KN, Grando CP. Sais anestésicos utilizados na Odontologia: revisão de literatura. J Oral Investig. 2017;6(1):75-84.

33. Gordh T. Lidocaine: the origino of a modern local anesthetic. Anesthesiology. 2010;113(6):1433-37.

34.Peñarrocha M, Sanchis BJM, Martínez GJM. Anestesia local em Odontologia. Rio de Janeiro: Guanabara Koogan; 2008.

35.DEF. Dicionário de especialidades farmacêuticas 2016. 44. ed. Rio de Janeiro: Publicações Científicas; 2016.

36. Vasconcelos RJH, Nogueira RVB, Leal AKR, Oliveira CTV, Bezerra JGB. Alterações sistêmicas decorrente do uso da lidocaína e prilocaína na prática odontológica. Rev cir traumatol buco-maxilo-fac. 2002;1(2):13-19.

37.Montan MF, Cogo K, Bergamaschi CC, Volpato MC, Andrade ED. Mortalidade relacionada ao uso de anestésicos locais em Odontologia. RGO. 2007;55(2):197-202.

38.Gaffen AS, Haas DA. Survey of local anesthetic use by ontario dentists. J Can Dent Assoc. 2009;75(9):649.

39. Souza LMA, Ramacciato JC, Motta RHL. Uso de Anestésicos locais em pacientes idosos. RGO. 2011;59:25-30.

40. Yagiela JA, Dowd FJ, Johnson BS, Mariotti AJ, Neidle EA. Farmacologia e terapêutica para dentistas. 6. ed. Rio de Janeiro: Elsevier; 2011.

41.Mojumdar EH, Lyubartsev AP. Molecular dynamics simulations of local anesthetic articaine in a lipid bilayer. Biophys Chem. 2010; 153(1):27-35.

42.Maniglia-Ferreira C, Almeida-Gomes F, Carvalho-Sousa B, Barbosa AV, Lins CC, Souza FD et al. Clinical evaluation of three anesthetics in endodontics. Acta Odontol Latinoam. 2009; 22(1):21-6.

43. Moore PA, Doll B, Delie RA, Hersh EV, Korostoff J, Johnson $\mathrm{S}$ et al. Hemostatic and anesthetic efficacy of $4 \%$ articaine HCL with 1:200,00 epinephrine and 4\% articaine HCL with 1:100,000 epinephrine when administrated intraorally for periodontal surgery. J Periodontol. 2007;78(2):247-53.

44. Santos CF, Modena KC, Giglio FP, Sakai VT, Calvo AM, Colombini BL et al. Epinephrine concentration $(1,100,00$ or $1,200,000)$ does not affect the clinical efficacy of $4 \%$ articaine 
forlower third molar removal: a double-blind, randomized, cross study. J Oral Maxillofac Surg. 2007;65(12):2445-52.

45. Massaro F. Lipossomal bupivacaine: a long-acting local anesthetic for postsurgical analgesia. Focus On. 2012; 47:213-26.

46.Dantas MVM, Gabrielli MAC, Hochuli VE. Effect of mepivacaine $2 \%$ with adrenaline $1: 100.000$ in blood pressure. Rev Odontol UNESP. 2008;37(3):223-27.

\section{CONFLITO DE INTERESSES}

Os autores declaram não haver conflitos de interesse.

\section{AUTOR PARA CORRESPONDENCIA}

José Henrique de Araújo Cruz henrique_araujo1992@ hotmail.com

Submetido em 26/03/2019

Aceito em 28/08/2019 